\title{
O PAPEL DO MEDIADOR NA IDENTIFICAÇÃO E COMBATE À SÍNDROME DE ALIENAÇÃO PARENTAL
}

\author{
THE ROLE OF THE MEDIATOR IN IDENTIFYING \\ AND COMBATING PARENTAL ALIENATION SYNDROME
}

\begin{abstract}
Henata Mariana de Oliveira Mazzoni
Advogada pela Instituição Toledo de Ensino (Bauru-SP) e Psicóloga pela Universidade do Sagrado Coração (Bauru-SP). Especialista em Didática e Metodologia do Ensino Superior pelo Centro Universitário Anhanguera. Atualmente cursa especialização em Psicologia Jurídica pela Universidade do Sagrado Coração. Agente de Defensoria - Psicóloga - na Defensoria Pública do Estado de São Paulo. Professora do curso de Direito da Faculdade Anhanguera de Bauru(SP).

h.mazzoni@ig.com.br
\end{abstract}

\section{RESUMO}

O presente estudo se propõe, através de uma apreciação crítica, baseada em pesquisa bibliográfica, a analisar como o mediador familiar pode identificar e atuar durante a mediação familiar no combate à Síndrome de Alienação Parental. 0 processo de divórcio é sempre muito difícil e, mesmo quando consensual acaba gerando sofrimento principalmente nos filhos. Muitos genitores inconformados com o fim do relacionamento ou com a nova união do ex companheiro, acabam convencendo os filhos contra o outro genitor despertando na criança sentimentos de ódio e o afastamento do genitor. A mediação familiar dá a oportunidade de um casal em processo de divórcio refletir, dialogar e se responsabilizar pela situação dos filhos após o fim do relacionamento e o mediador, ao identificar os sinais da Síndrome de Alienação Parental durante a mediação, pode minimizar os danos

Palavras-chave: Alienação; Divorcio; Guarda. Mediação.

\section{SUMÁRIO}

INTRODUÇAO; 1.FAMÍLIA CONTEMPORÂNEA E O DIVÓRCIO; 2. A MEDIAÇÃO COMO MEIO DE SOLUÇÃO PACÍFICA DE CONFLITOS; 3. A SÍNDROME DA ALIENAÇÃO PARENTAL 4. O PAPEL DO MEDIADOR DIANTE DA SÍNDROME DE ALIENAÇÃO PARENTAL; CONCLUSÃO; REFERÊNCIAS

\begin{abstract}
The present study aims, through a critical appraisal, based on research literature, the examining how the family mediator can identify and act during family mediation in combating parental alienation syndrome. The process of divorce is always difficult, and even when it is consensual generates suffering on children. Many parents unhappy with the end of the relationship or the new union of old partner end up persuading children against the other parent what raise on them feelings of hate and consequently the alienation of the parent. The family mediation provides the opportunity for a divorcing couple to reflect, discuss and take responsibility for the situation of children after the relationship and the mediator when identifying the sings of parental alienation syndrome during mediation can minimize the damage.
\end{abstract}

Keywords: Alienation; Divorce; Custod; Mediation. 


\section{INTRODUÇÃO}

Nas ultimas décadas houve uma mudança muito grande no conceito e organização da entidade familiar.

Antes, na maioria dos casos o que unia as pessoas matrimonialmente era a conveniência, principalmente a conveniência patrimonial. Hoje, prima-se pela felicidade, poucos mantém uma união que não seja pelo objetivo de ser feliz.

Ocorre que com o fim da união matrimonial e da convivência entre os pares, os filhos fruto dessas uniões acabam muitas vezes ficando desamparados, sendo vítimas da obstrução do direito à convivência com um dos genitores (principalmente o genitor que não detém a guarda).

O fim de um relacionamento não deve condenar os filhos à infelicidade, muito pelo contrário, o relacionamento entre os genitores acabou, mas ambos continuarão desempenhando seus papéis parentais por toda a vida. Desta forma, devem os pais, amenizar o máximo possível o sofrimento de seus filhos em decorrência da separação.

Umas das formas de amenizar o sofrimento com o fim do relacionamento é exercer principalmente de forma qualitativa, o direito de convivência, pois, sabemos que a convivência com ambos os genitores, mesmo após o fim do relacionamento conjugal, é essencial para o desenvolvimento saudável dos filhos.

Levar a questão da estipulação de guarda e visitas ao juiz torna-se por vezes cômodo, pois nesse sentido isentam-se os pais de refletirem e se responsabilizarem pelas decisões que dizem respeito principalmente ao bem estar dos filhos.

Para evitar esse comodismo e ajudar as partes a decidirem elas mesmas o futuro, surge a mediação que é uma modalidade de acordo onde, na presença de terceiros (geralmente mediador e co-mediador), as partes podem refletir, dialogar e decidir com total responsabilidade sobre o futuro de sua prole.

Infelizmente algumas vezes o fim do relacionamento gera, em um dos genitores, sentimentos de raiva e vingança para com o outro genitor, principalmente se este já constituiu uma nova família. Com o objetivo de vingança e destruição do outro cônjuge envolve os filhos, fazendo com que estes passem a odiá-lo, chegando muitas vezes ao ponto de implantar falsas 
memórias de abusos nas crianças. Esse é o cenário da conhecida Síndrome de Alienação Parental (SAP), algumas vezes presente nos processos de divórcio.

A mediação familiar proporciona oportunidade de reflexão, diálogo e comprometimento dos pais em relação ao bem estar dos filhos depois do divórcio. Diante disso, questiona-se: pode ela evitar, ou ao menos amenizar, o sinais da Síndrome de Alienação Parental? Qual o papel do mediador diante da ocorrência da Síndrome de Alienação Parental?

O presente estudo tem como objetivo identificar, através de pesquisa bibliográfica, os sinais da Síndrome de Alienação Parental e o papel do mediador diante da ocorrência da mesma no processo de mediação.

Primeiramente abordaremos a questão do divórcio na sociedade atual, em seguida falaremos sobre a Síndrome da Alienação Parental e, por fim, sobre o instituto da mediação e o papel do mediador principalmente na prevenção e combate à Síndrome de Alienação Parental

\section{A FAMÍLIA CONTEMPORÂNEA E O DIVÓRCIO}

As transformações que a família sofreu ao longo das ultimas décadas são evidentes.

Hoje temos famílias formadas por pais solteiros e seus filhos, pais divorciados, pais divorciados e casados novamente, com companheiros e seus filhos de outros casamentos e famílias compostas por casais homossexuais.

Até o advento do desenvolvimento industrial a família era considerada um grupo sólido. Não se pensava em separação conjugal. A grande preocupação dos pais e seus inúmeros filhos era apenas com a subsistência. Com o passar do tempo, a mulher saiu para o mercado de trabalho, assumindo dupla jornada e, com isso, mostrou-se insatisfeita com a falta de ajuda do companheiro com a casa e a criação dos filhos. Na sociedade atual vemos uma mudança de valores muito grande, evidenciada pela preocupação com a realização profissional em detrimento das relações pessoais. ${ }^{1}$

Alguns estudiosos afirmam que a família está em crise, contudo, o que na verdade ocorre é a mudança de paradigma a respeito de família.

1 CASTRO, L.R. Disputa de guarda e visitas: no interesse dos pais ou dos filhos? São Paulo: Casa do Psicólogo, 2003 
No passado, ainda com a proibição do divórcio, muitos filhos eram condenados a conviver com seus pais em crise, presenciando hostilidade e a discórdia entre eles porque era inconcebível na visão da sociedade um casal divorciado.

Essa cena mudou. Hoje prima-se pela felicidade. Já não se vive mais junto com alguém por conveniência, mas sim para ser feliz.

Além do mais, o próprio Estado oferece proteção à família, por reconhecê-la como base da sociedade, como vemos como vemos explicitado na Constituição Federal ${ }^{2}$ :

Art. 226. A família, base da sociedade, tem especial proteção do Estado (...)

$\S 7^{\circ}$ - Fundado nos princípios da dignidade da pessoa humana e da paternidade responsável, o planejamento familiar é livre decisão do casal, competindo ao Estado propiciar recursos educacionais e científicos para o exercício desse direito, vedada qualquer forma coercitiva por parte de instituições oficiais ou privadas. (BRASIL. Constituição da República Federativa do Brasil).

O texto constitucional não mais limita à formação familiar como aquela que se consolida apenas através do casamento, mas reconhece a União Estável como entidade familiar, bem como estende esse conceito à comunidade formada por qualquer um dos pais e seus descendentes. A família passou a ser entendida como grupo de pessoas ligadas através de vínculos consangüíneos (parentesco natural) ou civis (adoção) ${ }^{3}$.

As mudanças sociais ocorrem em uma velocidade maior que as mudanças na legislação. Dias (2010), afirma que a sociedade está em processo constante de mudanças. Apesar disto, o legislador não consegue acompanhar as mudanças na legislação no mesmo ritmo das mudanças na sociedade. Mesmo assim, há a necessidade de se empreender esforços para que possa o Direito amparar os anseios da sociedade em evolução.

Até pouco tempo, crianças nascidas fora do casamento e filhos de pais divorciados sofriam com o estigma e preconceito. Até entre os estudiosos era consenso que uma criança precisava crescer em uma família nuclear conjugal, para ter um desenvolvimento saudável. Havia poucos estudos no sentido de identificar como crianças e adolescentes viviam a separação dos pais e o que seria necessário para a transição da família conjugal para a divorciada. Atualmente, sabe-se que grande parte dos filhos de pais divorciados conseguem se adaptar à

2 BRASIL. Constituição da República Federativa do Brasil. 8. ed. São Paulo: Revista dos Tribunais, 2003. RT Legislação.

${ }^{3}$ GARCIA, E.M.S. Direito de Família: Principio da Dignidade da Pessoa Humana. Leme: Editora de Direito, 2003 
nova vida sem que isso traga dificuldades a longo prazo. Contudo, isso só é possível a medida que se busque minimizar o impacto desta transição ${ }^{4}$.

Evidente que as pessoas têm o direito a reconstruir suas vidas depois de um casamento frustrado, contudo, o que deve ser evitado é que os filhos paguem o preço pelo fracasso do relacionamento.

Importante salientar que com o fim do relacionamento surge a necessidade de regulamentação da guarda e regime de visitas aos filhos menores, pois “...a cessação da convivência entre os pais não faz cessar a convivência familiar entre os filhos e seus pais, ainda que estes passem a viver em residências distintas" ${ }^{5}$.

O genitor que não detém a guarda deve empreender esforços para estar o máximo de tempo possível com o filho, para que desta maneira a criança não sofra com sua ausência uma vez que ficou só com as visitas.

Téoricos estudiosos do desenvolvimento infantil afirmam que o bem estar e o desenvolvimento físico, emocional, intelectual e social da criança está relacionado com o envolvimento frequente e positivo dos genitores com seu filho desde os primeiros meses de vida. ${ }^{6}$

0 que se deve evitar é que, com o fim do relacionamento, a criança perca o contato com um de seus genitores.

Estudos comprovam que as crianças que, efetivamente, se distanciam do genitor após o divórcio, não têm um desempenho tão bom, sobre vários aspectos, entre eles escolares e sociais, quanto as que têm um pai emocionalmente disponível. ${ }^{7}$

Com o crescente número de divórcios, surge a necessidade de amparar os filhos e garantir a eles apesar do fim do relacionamento, a continuação da convivência com ambos os genitores.

Falar em guarda de filhos pressupõe a separação dos pais. Porém, o fim do relacionamento dos pais não pode levar à cisão dos direitos parentais. 0 rompimento do vínculo familiar não deve comprometer a continuidade da convivência dos filhos com ambos os genitores. É preciso que eles não se sintam objeto de vingança em face dos ressentimentos dos pais". ${ }^{8}$

\footnotetext{
${ }^{4}$ SOUZA, R.M. RAMIRES, V.R. Amor, casamento, família e divórcio...e depois, segundo às crianças.São Paulo: Summus, 2006.

${ }^{5}$ LÔBO, Paulo Luiz Netto. Direito Civil: Famílias. 2. ed. São Paulo: Saraiva, 2009 p.168.

${ }^{6}$ CARREIRA ET AL, 2000; KELLEY, SMITH, GREEN BERNDT \& ROGERS, 1998; SHANNON, TAMIS LE MONDA, LONDON E CRABRERA In: PAPALI, D.E.; OLDS, S.W; FELDMAN, R.D. 0 mundo da criança: da Infância à adolescência. São Paulo: McGraw - Hill, 2009

7 TEYBER E. Ajudando crianças a conviver com o divórcio. São Paulo: Nobel, 1995

${ }^{8}$ DIAS, Maria Berenice. Manual de Direito de Família. 6.ed. São Paulo: Revistas dos Tribunais, 2010. p.398
} 
Para isso, surgiu a guarda compartilhada, infelizmente ainda mal compreendida e pouco aplicada pelos operadores do Direito.

A guarda compartilhada implica em igualdade de direitos e responsabilidades e principalmente, na continuidade da convivência dos genitores em relação à prole, após o fim do relacionamento conjugal.

Para Grisard Filho ${ }^{9}$ no que diz respeito ao exercício da parentalidade, o modelo de guarda compartilhada é mais eficaz à continuidade das relações dos filhos com os pais, buscando na família dissociada a semelhança da família intacta. Nesta modalidade de guarda os pais que vivem separados podem exercer conjuntamente a autoridade parental, conforme faziam durante a união conjugal.

$\mathrm{Na}$ intenção de tornar os pais cada vez mais participativos e presentes na vida de seus filhos, a guarda compartilhada evita, também, a discórdia no sentido de proporcionar ao genitor que não detém a guarda maior contato com os filhos, evitando desta maneira insatisfações e conflitos pela falta de contato com os filhos

Guarda conjunta ou compartilhada significa mais prerrogativas aos pais, fazendo com que estejam presentes de forma mais intensa na vida dos filhos...A proposta é manter os laços de afetividade, minorando os efeitos que a separação acarreta nos filhos e conferindo aos pais o exercício da função parental de forma igualitária. ${ }^{10}$

A modalidade de guarda compartilhada procura atuar no melhor interesse da criança, pois permite que haja uma divisão de responsabilidades entre os pais separados no que concerne a participação nas principais decisões em relação aos filhos.

É bem verdade que não são em todos os casos cabíveis a modalidade de guarda compartilhada, pois uma de suas condições é que os genitores tenham um bom relacionamento, baseado principalmente no diálogo.

\footnotetext{
${ }^{9}$ GRISARD FILHO, Waldyr. Guarda Compartilhada - Quem Melhor para Decidir? São Paulo: Pai Legal, 2002. Disponível em:

<http:/ / www. pailegal.net/TextoCompleto.asp?lsTextoTipo=Justica\&toffset=10\&lsTextold=1094972355>. Acesso em: 15 agosto 2011.

${ }^{10}$ DIAS, Maria Berenice. Manual de Direito de Família. 6.ed. São Paulo: Revistas dos Tribunais, 2010. p.401
} 
Vemos que as mudanças na formação da família foram significativas, contudo, a participação dos pais na vida dos filhos, atuando de forma responsável, mesmo vivendo em lares separados, é essencial para o desenvolvimento saudável das crianças e adolescentes.

\section{A MEDIAÇÃO COMO MEIO DE SOLUÇÃO PACÍFICA DE CONFLITOS}

O conflito está presente em todas as relações humanas, ocasionado por diferentes modos de pensar, diferentes interesses. O que determina o desenrolar do conflito é a capacidade de interação entre as pessoas, ou seja, a comunicação.

A dificuldade ou a falta de comunicação é hoje um dos principais obstáculos para uma salutar convivência em sociedade.

Sabe-se que o conflito não acarreta somente prejuízos para as pessoas e à sociedade no geral, dependendo do modo como esse se desenvolve pode trazer também uma melhora nas relações de convivência social.

Segundo Fiorelli e Malhadas ${ }^{11}$ diante de um processo de conflito benéfico e educativo, o individuo amplia não só o autoconhecimento, mas também sua visão de mundo e aprende a lidar melhor com as dificuldades impostas pela convivência em sociedade.

A mediação surge então para facilitar o processo de comunicação entre as partes envolvidas em um conflito, fazendo com que mediadas por uma terceira pessoa, consigam elas mesmas chegar a um acordo mutuamente aceitável.

A mediação, é “um método de condução de conflitos, aplicado por um terceiro neutro e especialmente treinado, cujo objetivo é restabelecer a comunicação produtiva entre as pessoas que se encontram em um impasse, ajudando-as a chegar a um acordo". ${ }^{12}$

Reconhecido como um principio que orienta a mediação, a autonomia da vontade das partes surge no sentido de que não poderá jamais ser imposta a mediação para solução de conflitos, pois, não estando as partes dispostas ao diálogo, disposta a ceder, a olhar o outro e suas motivações, a mediação jamais resultará frutífera.

\footnotetext{
${ }^{11}$ Fiorelli, J.O ; MALHADAS, M.J. Psicologia aplicada ao direito São Paulo: Ltr,2006.

${ }^{12}$ NAZARETH, E.R. Guia de mediação familiar: aspectos psicológicos In: NAZARETH, E.R. VILELA, S.R., GUEDES- PINTO, A.C.R. Mediação familiar. São Paulo: Equilibrio, 2009 p.21
} 
Não temos ainda legislação para regulamentar a mediação, mas está tramitando no Congresso nacional o projeto de lei 4.827/98. O referido projeto traz a definição de mediação: "A atividade técnica exercida por terceira pessoa, que escolhida ou aceita pelas partes interessadas, as escuta e orienta com o propósito de lhes permitir que, de modo consensual, previnam ou solucionem conflitos”. O projeto propõe duas formas de mediação: a mediação prévia antes de iniciar o processo e incidental, depois de iniciado. Ambas são facultativas, podendo ser realizadas por mediadores judiciais que são advogados com três anos de experiência jurídica ou extrajudiciais, onde atuam profissionais de outras áreas que trabalham com mediação. $^{13}$

A mediação sempre que possível deve ser realizada por dois profissionais, ou seja, um mediador e outro co-mediador. 0 ideal é que seja um profissional com formação em Psicologia ou Serviço Social e outro com formação em Direito. Desta forma, numa visão multidisciplinar, um profissional complementa o outro no olhar acerca do conflito, bem como na atuação no processo de mediação. São visões diferentes mas que, por fim, se complementam.

Na mediação, a resolução do conflito não é imposta por um juiz ou um árbitro. Mas, têm as partes, autonomia para elegerem a melhor solução para sua contenda.

O mediador deve ser imparcial, neutro. Diferente do Juiz ou árbitro, ele não decide, apenas auxilia as partes no diálogo e apresenta sugestões hipotéticas, na intenção de clarear as idéias, emoções e pensamentos dos envolvidos no conflito. “O mediador, portanto, não impõe uma solução para o conflito. Seu papel consiste em promover o diálogo amigável, auxiliando as partes a encontrar um acordo em que a ambas satisfaça, fomentando o surgimento de uma nova realidade, a partir da relação continuada existente entre os mediados ${ }^{14}$

Como requisitos do processo de mediação estão a confidencialidade e o sigilo das informações. O mediador deve deixar isso sempre claro às partes, enfatizando que tudo o que for dito a ele, não será compartilhado com mais ninguém.

Além de não ser arbitro ou juiz, o mediador não é psicoterapeuta, ou seja, não faz psicoterapia, não explora os conflitos intrapessoais e nem os temas emocionais. Quando preciso for, encaminha a parte ou as partes à terapia. 0 mediador também não atua na mediação como

\footnotetext{
${ }^{13}$ SALES, Lília Maia de Morais; VASCONCELOS, Mônica Carvalho. Mediação familiar, um estudo históricosocial das relações de conflitos nas famílias contemporâneas. Fortaleza: Expressão Gráfica, 2006. 14 p.72
} 
advogado, não defende uma parte ou outra, mas preocupa-se com ambas, mantendo sempre a imparcialidade ${ }^{15}$

$\mathrm{Na}$ conciliação, segundo alguns autores, o conciliador pode apresentar uma sugestão ou recomendação ao caso em tela. Ao contrário do árbitro ou conciliador, o mediador tem um papel de facilitador do processo, ele não propõe alternativas, ele apenas auxilia as partes a tomar suas decisões de forma a se responsabilizarem por elas.

Sendo o mediador puramente um facilitador do processo não poderá expressar qualquer opinião sobre o mérito.

Um dos objetivos da mediação é a celeridade na solução dos conflitos, onde esses são resolvidos em algumas sessões, ao passo que na Justiça Comum poder-se-ia levar anos, para chegar a uma solução final. E, também, a diminuição da sobrecarga do poder judiciário, uma vez que um acordo eficaz com a participação das próprias partes, realizado em mediação, evitará que a questão chegue ao judiciário.

Um acordo mediado, onde os pais resolvem as contendas, buscando o mútuo consentimento, é mais benéfico para o filho, do que levar a questão aos tribunais, passando por todo desgastante processo judicial, deixando a solução para suas vidas nas mãos do judiciário.

[...] Quando os pais resolvem as controvérsias no tribunal, a aspereza, a amargura e a desconfiança entre eles são sempre exacerbadas pelo processo de litígio judicial. Na maioria dos casos, o ódio resultante perdura por décadas. Os filhos sofrem imensamente quando veem seus pais brigando no tribunal, e ficam magoados com a hostilidade entre eles. Além desses benefícios emocionais para pais e filhos igualmente, os acordos mediados são muito menos caros que as lutas judiciais. E, em geral, os acordos mediados são mais flexíveis que as soluções ditadas pelo juiz, porque podem ser alterados por mútuo consentimento, em vez de terem um encaminhamento legal. Assim, recomenda-se enfaticamente aos pais divorciados fazer esforços sinceros para resolver suas controvérsias via mediação, antes de partir para o processo judicial, altamente perturbador e litigioso". ${ }^{16}$

Além disso, segundo Breitman e Porto ${ }^{17}$, o objetivo da mediação não é reconciliar um casal em crise, mas estabelecer uma via de comunicação que evite uma batalha judicial. É uma maneira de auxiliar as partes, para que possam negociar suas contendas, pensando sempre em

\footnotetext{
${ }^{15}$ SAMPAIO, L.R.C. NETO, A.B. $O$ que é mediação de conflitos. São Paulo: Brasiliense, 2007.

${ }^{16}$ TEYBER E. Ajudando crianças a conviver com o divórcio. São Paulo: Nobel, 1995 p.137

${ }^{17}$ BREITMAN Stella; PORTO, Alice Costa.Mediação Familiar: Uma intervenção em busca da paz. Porto Alegre: Criação Humana, 2001
} 
seus filhos, pois mesmo com o fim do relacionamento conjugal a relação parental jamais deixará de existir.

Assumindo-se suas vidas e decisões as partes podem se comprometer a cumprir o que foi acordado, mais que ao obedecer a uma ordem imposta pelo juiz.

É inegável que a proposta trazida pela mediação de fazer com que as partes pensem por si mesmas para chegarem a um acordo é muito bem vinda. Contudo, não devemos aplicar a mediação em todos os casos, sem critérios. Cuevas apud Castro afirma que “...há fatores que fazem a mediação fracassar. Dentre eles coloca-se as personalidades paranóicas e psicopatas e/ou separações traumáticas". ${ }^{18}$

O diálogo, a comunicação entre as partes, é uma premissa da mediação. 0 mediador é apenas um facilitador, portanto, casais que ainda estão num processo de mágoa muito exacerbado que nem ao menos conseguem se olhar, terão extrema dificuldade em participar do processo de mediação.

Sales ${ }^{19}$ apresenta alguns princípios que regem a mediação:

O Princípio da liberdade das partes: significa que as partes envolvidas no litígio devem ser livres, não devem se sentir ameaçadas ou coagidas a aceitar um acordo que não julguem eficaz.

O Princípio da não-competitividade: deve-se buscar uma solução que seja satisfatória para ambas as partes. Não se incentiva a competição, mas a cooperação.

O Princípio do poder de decisão das partes: a decisão sempre cabe às partes. 0 mediador apenas facilita a comunicação, não podendo tomar qualquer decisão em nome das partes

O Princípio da participação de terceiro imparcial: o mediador não deve desenvolver suas atividades de modo a beneficiar uma das partes.

Princípio da competência: o mediador deve ser apto para desempenhar suas funções. Deve possuir, dentre outras características, a diligência, a prudência e o cuidado.

O Princípio da informalidade do processo: na mediação não há uma formalidade no sentido de procedimentos a ser rigidamente seguidos, como no processo judicial, apresentando assim diversas formas de ser conduzida.

\footnotetext{
${ }^{18}$ CASTRO, L.R. Disputa de guarda e visitas: no interesse dos pais ou dos filhos? São Paulo: Casa do Psicólogo, 2003 p.29

${ }^{19}$ SALES, Lília Maia de Morais. Justiça e mediação de conflitos. Belo Horizonte: Del Rey, 2004.
} 
Por fim, pelo Princípio da confidencialidade no processo, o mediador deve guardar sigilo em relação ao que se discute na mediação.

A resolução $n^{\circ} 125$ de 29 de novembro de 2010 do Conselho Nacional de Justiça instituiu a conciliação e mediação como meios consensuais de resolução de conflito, devendo os tribunais criar os centros judiciais de solução de conflito e cidadania.

Para Ferraz ${ }^{20}$, o CNJ ao lançar o programa pela conciliação contribui para que a comunidade e os órgãos judiciários possam rever alguns conceitos baseados na idéia de que a conciliação não só traz maiores benefícios às partes e ao próprio judiciário com a diminuição das demandas judiciais conforme preceitua a Constituição Federal.

Uma disputa judicial acarreta sempre um desgaste emocional muito grande, as partes muitas vezes não têm condições de visualizar situações, além daquelas que ditam o seu interesse. Vêem o lado oposto como um adversário, um inimigo. A disputa judicial é finalizada com um vencedor e um perdedor. A mediação traz mudança de mentalidade onde o outro não é um inimigo, mas sim uma pessoa que também tem seus interesses. Através do diálogo, as partes podem perceber o lado oposto, buscando uma solução que seja favorável a ambas e que não haja simplesmente vencedor e perdedor.

\section{A SÍNDROME DA ALIENAÇÃO PARENTAL}

Quando a união acaba os genitores precisam amenizar o sofrimento dos filhos, principalmente o sofrimento ocasionado pela ausência do genitor que sai do lar familiar.

Espera-se que a criança com o fim do relacionamento possa continuar desfrutando da convivência com o pai e a mãe em igualdade de condições, buscando dessa forma evitar o sentimento de abandono.

A ausência principalmente afetiva de um dos pais pode causar na criança consequências muito graves que não exatamente no âmbito material. A separação com a determinação de um tipo de guarda que não atenda às necessidades da criança, levando à ausência de um dos pais, pode interferir no desenvolvimento saudável do filho ${ }^{21}$.

\footnotetext{
${ }^{20}$ FERRAZ, Taís Schilling A conciliação e sua efetividade na solução dos conflitos. Disponível em: portal.tjpr.jus.br/c/document_library/get_file?folderld=328895...doc. Acesso em: 01 - agosto-2011 ${ }^{21}$ SILVA, Evandro L. Guarda de filhos: aspectos psicológicos. In: Associação de Pais e Mães Separados. Guarda compartilhada: aspectos psicológicos e jurídicos. Porto Alegre: Equilíbrio, 2005.
} 
Contudo, muitas vezes o ex casal não têm essa consciência. Alguns cônjuges atuam de modo a impedir que o outro possa desfrutar da convivência com os filhos.

Hoje é reconhecida pelos juristas e operadores do Direito a ocorrência da Síndrome da Alienação Parental principalmente em disputas judiciais pela guarda dos filhos. Alguns genitores no intuito de ficar com a guarda dos filhos os induzem a falar mal do outro genitor, para desta forma atingir seus interesses.

A síndrome de alienação parental foi descrita pela primeira vez pelo psiquiatra americano Richard Gardner:

A Síndrome de Alienação Parental (SAP) é um distúrbio da infância que aparece quase exclusivamente no contexto de disputas de custódia de crianças. Sua manifestação preliminar é a campanha denegritória contra um dos genitores, uma campanha feita pela própria criança e que não tenha nenhuma justificação. Resulta da combinação das instruções de um genitor (o que faz a "lavagem cerebral, programação, doutrinação") e contribuições da própria criança para caluniar o genitor-alvo. Quando o abuso e/ou a negligência parentais verdadeiros estão presentes, a animosidade da criança pode ser justificada, e assim a explicação de Síndrome de Alienação Parental para a hostilidade da criança não é aplicável. ${ }^{22}$

A criança nos casos de Síndrome da Alienação Parental é "programada" por um dos genitores para renegar, se afastar e odiar o outro genitor, o que resulta em sofrimento intenso para o genitor alienado e principalmente para a criança.

Nos casos descritos como Síndrome de Alienação Parental,o genitor alienador que geralmente é aquele que detém a guarda da criança, empreende esforços para que o filho tenha pensamentos e sentimentos totalmente desfavoráveis em relação ao outro genitor, objetivando o afastamento e destruindo os vínculos existentes entre os filhos e o ex cônjuge. ${ }^{23}$.

A criança passa a ter o genitor alienado como um verdadeiro estranho, enquanto isso tem como modelo o genitor alienador com todas as características patológicas. Diante dessa situação, a criança tende a reproduzir a mesma patologia de que sofre o genitor alienante aprendendo a odiar o genitor alienado. ${ }^{24}$

\section{${ }^{22}$ GARDNER, Richard A. O DSM-IV tem equivalente para o diagnóstico de Síndrome de Alienação} Parental (SAP)? Disponível em http://www.alienacaoparental.com.br/textos-sobre-sap-1/o-dsm-iv-temequivalente. Acesso em 20 de maio de 2010

${ }^{23}$ MOTTA, Maria A. P. A Síndrome da Alienação Parental In: Associação de Pais e Mães Separados. Síndrome de alienação parental e a tirania do guardião. Porto Alegre: Equilíbrio, 2008.

${ }^{24}$ SILVA, Denise M. P. Psicologia jurídica no processo civil brasileiro. 1a. e.d. São Paulo: Casa do Psicólogo, 2003 
0 genitor alienador expõe aos filhos com riquezas de detalhes suas experiências negativas, sentimentos ruins e todo sofrimento causado pelo genitor alienado, fazendo com que as crianças absorvam todo esse referencial.

Os motivos que levam o genitor ao comportamento alienador são vários. Vão desde ciúmes pelo fato do ex companheiro iniciar um novo relacionamento, inconformismo pelo fim do relacionamento e conseqüente declínio no padrão sócio-econômico comparado ao que tinha pela ocasião da união, até a pura e simples maldade, característica da personalidade perversa.

Em manifestações de grande egoísmo, não visam o melhor interesse da criança, mas a satisfação de sentimentos pobres como a vingança e a punição ao ex companheiro.

Apresentam muitas vezes frieza emocional, percebidas ao relatar situações que deveriam trazer-lhes sofrimento, como se a eles não dissessem respeito, ou como se não percebessem o sofrimento causado ao filho.

Podemos notar alguns comportamentos típicos do genitor alienador conforme Gardner apud Motta ${ }^{25}$ elenca:

a)Recusar-se a passar as chamadas telefônicas aos filhos; b) Organizar várias atividades com os filhos durante o período que o outro genitor deve normalmente exercer o direito de visitas; c) Apresentar o novo cônjuge aos filhos como sua nova mãe ou seu novo pai e, por vezes, insiste que a criança utilize esse tratamento pessoal; d)Interceptar as cartas e os pacotes mandados aos filho. e) Desvalorizar e insulta o genitor na frente dos filhos; f) Recusar informações ao outro genitor sobre as atividades em que os filhos estão envolvidos (esportes, atividades escolares, grupos teatrais, etc); g) Falar de maneira descortês ao novo cônjuge do outro genitor; h)Impedir o outro genitor de exercer seu direito de visita; i) "Esquecer" de avisar, o outro genitor, de compromissos importantes (dentistas, médicos, psicólogos); j) Envolver pessoas próximas (sua mãe, seu novo cônjuge, etc) na lavagem cerebral de seus filhos; k) Tomar decisões importantes a respeito dos filhos, sem consultar o outro genitor (escolha da religião, escolha da escola, etc); l) Trocar (ou tentar) trocar seus nomes e sobrenomes; m) Impedir o outro genitor de ter acesso às informações escolares e/ ou médicas de seus filhos; n)Sair de férias sem os filhos e deixá-os com outras pessoas que não o outro genitor, ainda que este esteja disponível e queira ocupar-se dos filhos; o) Falar aos filhos que a roupa que o outro genitor comprou é feia e proibi-los de usá-la; p)Ameaçar punir os filhos, se eles telefonarem, escreverem ou se comunicarem com o outro genitor de qualquer maneira; q) Culpar o outro genitor pelo mau comportamento do filho.

${ }^{25}$ MOTTA, Maria A. P. A Síndrome da Alienação Parental In: Associação de Pais e Mães Separados. Síndrome de alienação parental e a tirania do guardião. Porto Alegre: Equilíbrio, 2008. 
Encontramos também na Síndrome de Alienação Parental o conflito de lealdade, onde o genitor alienador começa a usar a criança como aliada em suas empreitadas contra o outro genitor. A criança diante do conflito não pode nunca afirmar, por exemplo, que gosta de estar com o genitor alvo, que se divertiu quando estava com ele, ou até mesmo que quer passar mais tempo com ele, isso tudo pelo medo de desagradar o alienador.

Nos casos de conflito de lealdade, os filhos são pressionados a escolher um dos pais. Segundo Teyber, ${ }^{26}$ não há nenhuma criança que possa fazer essa escolha sem vivenciar um grande conflito interior. Os filhos normalmente querem relacionar-se com os dois genitores e sentem-se despedaçados por dentro, quando precisam fazer a escolha de um dos genitores em detrimento do outro.

O conflito de lealdade gera na criança além da angustia, uma ansiedade muito grande por ter que agir sempre, seguindo as instruções e a opinião do alienador. Segundo Resende e Silva ${ }^{27}$ são crianças que vivem uma ansiedade constante, patológica, sempre se defendendo e no constante esforço para não decepcionar o alienador

Muitas vezes o genitor alienador chega a usar chantagens e ameaças para que a criança possa obedecer e agir conforme the convém. Esta, com medo da rejeição e abandono, acaba aliando-se ao alienador. Configura-se nesses casos um verdadeiro abuso emocional contra a criança.

A Síndrome da Alienação Parental pode ocorrer sob a forma de falsas denuncias de abuso sexual envolvendo o genitor vítima, podendo chegar ao ponto de criar na criança falsas memórias do suposto abuso.

A narrativa de fatos que possam configurar uma aproximação incestuosa durante as visitas, faz com que o genitor extraia desse fato, verdadeiro ou não, a denúncia do incesto, convencendo o filho e levando-o a repetir o que é afirmado como se tivesse realmente acontecido. Ocorre que a crianças muitas vezes não conseguem diferenciar o que é fato real do que é manipulação baseada em afirmações fantasiosas, ditas de forma insistentemente

\footnotetext{
${ }^{26}$ TEYBER E. Ajudando crianças a conviver com o divórcio. São Paulo: Nobel, 1995 p.137

${ }^{27}$ RESENDE, M. SILVA, E.L. Síndrome da Alienação Parental: A exclusão de um terceiro. In: Associação de Pais e Mães Separados. Síndrome de alienação parental e a tirania do guardião. Porto Alegre: Equilíbrio, 2008.
} 
repetidas. Desta forma, a verdade do cônjuge alienador passa a ser a verdade para o filho. Está implantada a falsa memória do suposto abuso sexual. ${ }^{28}$

Diante dessa situação surge o desafio para os profissionais do Direito e peritos, apurarem, se houve ou não o suposto abuso o que se complica com as tentativas do cônjuge alienador de impedir que sejam realizados os exames.

O que acontece é que muitas vezes no momento da perícia para esclarecimentos dos fatos e constatação de eventuais abusos sexuais, o genitor alienador busque dificultar o trabalho dos profissionais, tentando manter seus filhos afastados dos examinadores. ${ }^{29}$

Aliás, o genitor alienador empreende esforços para afastar a criança de qualquer pessoa, sejam os profissionais examinadores, operadores do direito e até os demais familiares, que possam colocar em risco a versão apresentada pelo alienador, questionar ou contradizer suas denúncias.

Muitas vezes, o alienador faz alegações que em decorrência da gravidade levam os profissionais envolvidos a tomarem medidas na intenção de proteger a criança. Segundo Motta ${ }^{30}$, a tendência é que num primeiro momento se interrompa o contato da criança com o genitor acusado. A demora na apuração dos fatos é tanta, que o vínculo entre o genitor acusado e seus filhos fica irremediavelmente destruído.

O afastamento abrupto da criança com o genitor injustamente acusado é prejudicial, mas é o que ocorre na maior parte das vezes, quando uma denúncia desse grau chega ao judiciário. 0 juiz, como medida de proteção à criança, suspende visitas, ou determina visitas monitoradas. Também determina estudos sociais e psicológicos para constatar se houve ou não o tal abuso. Enquanto isso, a ausência do genitor na convivência com o filho pode causar sérias seqüelas emocionais ou psicológicas

\footnotetext{
${ }^{28}$ DIAS, Maria Berenice. Síndrome da alienação parental, o que é isso? . Jus Navigandi, Teresina, ano 10, n. 1119, 25 jul. 2006. Disponível em: <http://jus2.uol.com.br/doutrina/texto.asp?id=8690>. Acesso em: 21 maio 2010.

${ }^{29}$ MOTTA, Maria A. P. A Síndrome da Alienação Parental In: Associação de Pais e Mães Separados. Síndrome de alienação parental e a tirania do guardião. Porto Alegre: Equilíbrio, 2008.

${ }^{30}$ MOTTA, Maria A. P. A Síndrome da Alienação Parental In: Associação de Pais e Mães Separados. Síndrome de alienação parental e a tirania do guardião. Porto Alegre: Equilíbrio, 2008.
} 
$\mathrm{Na}$ verdade, muitos profissionais do Direito, da Psicologia, das áreas médicas e sociais não estão preparados técnica e emocionalmente para lidar com a questão de falsas acusações de abuso sexual, principalmente quando a criança é muito pequena e a comunicação é limitada. ${ }^{31}$

O legislador se empenhou em proteger as crianças que sofrem com a SAP ao criar a Lei da Alienação Parental (Lei n 12.318 de 26 de agosto de 2010).

A Lei traz em seu texto o conceito de alienação parental bem como exemplos de como a SAP pode se apresentar:

Art. $2^{\circ}$ Considera-se ato de alienação parental a interferência na formação psicológica da criança ou do adolescente, promovida ou induzida por um dos genitores, pelos avós ou pelos que tenham a criança ou adolescente sob a sua autoridade, guarda ou vigilância para que repudie o genitor, ou que cause prejuízo ao estabelecimento ou à manutenção de vínculos com este.

Parágrafo único. São formas exemplificativas de alienação parental, além dos atos assim declarados pelo juiz ou constatados por perícia, praticados diretamente ou com auxílio de terceiros:

I - realizar campanha de desqualificação da conduta do genitor no exercício da paternidade ou maternidade;

II - dificultar o exercício da autoridade parental;

III - dificultar contato de criança ou adolescente com genitor;

IV - dificultar o exercício do direito regulamentado de convivência familiar;

$\mathrm{V}$ - omitir deliberadamente a genitor informações pessoais relevantes sobre a criança ou adolescente, inclusive escolares, médicas e alterações de endereço;

$\mathrm{VI}$ - apresentar falsa denúncia contra genitor, contra familiares deste ou contra avós, para obstar ou dificultar a convivência deles com a criança ou adolescente;

VII - mudar o domicílio para local distante, sem justificativa, visando a dificultar a convivência da criança ou adolescente com o outro genitor, com familiares deste ou com avós.

0 artigo $5^{\circ}$ da Lei trata da perícia para apurar a existência da alienação. A avaliação psicológica ou biopsicossocial será realizada por equipe multiprofissional:

Art. $5^{\circ}$ Havendo indício da prática de ato de alienação parental, em ação autônoma ou incidental, o juiz, se necessário, determinará perícia psicológica ou biopsicossocial.

§ 1ํ O laudo pericial terá base em ampla avaliação psicológica ou biopsicossocial, conforme o caso, compreendendo, inclusive, entrevista pessoal com as partes, exame de documentos dos autos, histórico do relacionamento do casal e da separação, cronologia de incidentes, avaliação da personalidade dos envolvidos e exame da forma como a criança ou adolescente se manifesta acerca de eventual acusação contra genitor.

\footnotetext{
${ }^{31}$ CALÇADA, Andréia. Falsas acusações de abuso sexual: parâmetros iniciais para uma avaliação. In: Associação de Pais e Mães Separados. Guarda compartilhada: aspectos psicológicos e jurídicos. Porto Alegre: Equilíbrio, 2005
} 


\begin{abstract}
$\S 2^{\circ}$ A perícia será realizada por profissional ou equipe multidisciplinar habilitados, exigido, em qualquer caso, aptidão comprovada por histórico profissional ou acadêmico para diagnosticar atos de alienação parental. $\S 3^{\circ} \mathrm{O}$ perito ou equipe multidisciplinar designada para verificar a ocorrência de alienação parental terá prazo de 90 (noventa) dias para apresentação do laudo, prorrogável exclusivamente por autorização judicial baseada em justificativa circunstanciada.
\end{abstract}

Como conseqüência judicial para o genitor que pratica a alienação parental a lei dispõe que:

\begin{abstract}
Art. $6^{\circ}$ Caracterizados atos típicos de alienação parental ou qualquer conduta que dificulte a convivência de criança ou adolescente com genitor, em ação autônoma ou incidental, o juiz poderá, cumulativamente ou não, sem prejuízo da decorrente responsabilidade civil ou criminal e da ampla utilização de instrumentos processuais aptos a inibir ou atenuar seus efeitos, segundo a gravidade do caso:

I - declarar a ocorrência de alienação parental e advertir o alienador;

II - ampliar o regime de convivência familiar em favor do genitor alienado;

III - estipular multa ao alienador;

IV - determinar acompanhamento psicológico e/ou biopsicossocial;

V - determinar a alteração da guarda para guarda compartilhada ou sua inversão;

$\mathrm{VI}$ - determinar a fixação cautelar do domicílio da criança ou adolescente;

VII - declarar a suspensão da autoridade parental.

Parágrafo único. Caracterizado mudança abusiva de endereço, inviabilização ou obstrução à convivência familiar, o juiz também poderá inverter a obrigação de levar para ou retirar a criança ou adolescente da residência do genitor, por ocasião das alternâncias dos períodos de convivência familiar.
\end{abstract}

Como vimos, a Lei aplica ao genitor alienador sanções como advertência, multa, alteração da guarda até a suspensão do poder familiar. Contudo, sabemos que sem um efetivo acompanhamento psicossocial não só para o genitor alienante como para os filhos que sofreram as conseqüências da Alienação Parental não lograremos êxito em extinguir as atitudes alienadoras.

\title{
5 O PAPEL DO MEDIADOR DIANTE DA SÍNDROME DE ALIENAÇÃO PARENTAL
}

A mediação familiar nos casos de guarda e visita dos filhos se apresenta mais benéfica do que o processo judicial. Na mediação os genitores têm a possibilidade de refletir e dialogar, buscando eles mesmos o melhor interesse para os filhos, principalmente no sentido da convivência saudável com ambos os genitores. 
0 papel do mediador na área de família é de suma importância. O mediador deve ajudar o ex casal a chegar a um consenso buscando assim facilitar o diálogo entre as partes em processo de divórcio e conseqüente estabelecimento da guarda e visitas dos filhos.

Aguilar ${ }^{32}$, considera que os filhos de pais em processo de divórcio precisam de proteção pois, estão sujeitos a terem direitos violados e a mediação familiar nesses casos pode ajudálos a serem vistos como pessoas sujeitas de direitos.

$\mathrm{Na}$ mediação familiar algumas definições já se apresentam: nos casos de divórcio a mediação geralmente é feita com o casal, contudo pode estender-se também ao grupo familiar. 0 acordo dependerá tanto da habilidade do mediador como da disposição das partes em evitar a conduta litigiosa. O mediador deve contar com ajuda de outro profissional de outra área de atuação que será supervisor ou co-mediador. O mediador tem como foco a relação familiar e não aspectos individuais. Deve-se buscar o consenso, visando o melhor interesse dos filhos. ${ }^{33}$

Um dos benefícios que a mediação familiar traz para as partes, é protegê-las de expor em demasia suas vidas privadas. No Direito de Família os processos correm em segredo de justiça, contudo, mesmo assim, ainda haverá testemunhas a serem ouvidas, peritos, advogados e o promotor de justiça.

Em uma mediação familiar envolvendo guarda e visitas deve-se sempre levar em consideração o bem estar dos filhos, buscando como resultado uma boa convivência com ambos o genitores.

Um dos principais problemas a ser enfrentado num processo de divórcio é o genitor inconformado com o fim do relacionamento e, até mesmo, enciumado por outro relacionamento do ex parceiro passa a empreender esforços para que o filho tenha raiva do outro genitor, destruindo sua imagem para o filho que muitas vezes passa a evitá-lo e odiá-lo.

0 genitor que geralmente detém a guarda da criança, atua contra o outro genitor de modo a fazer uma verdadeira lavagem cerebral no filho. Isso pode ocorrer de várias formas, de maneira explícita ou dissimulada

\footnotetext{
${ }^{32}$ AGUILAR, José Manuel. Síndrome de alienação parental: filhos manipulados por um cônjuge para odiar o outro. Casal de Cambra: Caleidoscópio, 2008

${ }^{33}$ ROSA, Conrado Paulino da; SPENGLER, Fabriana Marion. A mediação como Política Pública de tratamento dos conflitos familiares. In: RODRIGUES, Hugo Thamir; COSTA, Marli M. M. da. (org.). Direito e Políticas Públicas III. Porto Alegre: Imprensa Livre, 2009, v. III, p. 155-178.
} 
O profissional que atua na mediação familiar precisa ficar atento aos sinais da Síndrome de Alienação Parental.

O papel do mediador é de suma importância. é um terceiro que, após escolhido ou aceito pelas partes intervém no conflito. Deve ser neutro, especialista na matéria a ser tratada, ser ético e guardar sigilo. Deve estar atento, neutralizando emoções. Quando estiver diante de sentimentos exacerbados ou seqüelas psicológicas ou morais, precisará primeiramente ouvir, depois intervir no sentido de levar as partes a entender as razões um do outro. Isso tudo, sem interferir diretamente na questão. ${ }^{34}$

Mais até do que levar as partes a entender as razões uma da outra, o mediador deve leválas a refletir sobre a situação dos filhos que, em geral, são os maiores prejudicados com o divórcio. Cabe também ao mediador estar atento à possíveis negligências, omissões e a existência da SAP por parte de um dos genitores.

A função do mediador, além de levar as partes à reflexão, é ajudá-las a se comunicar de forma precisa de forma a evitar mal entendidos, minimizar danos, prejuízos.

Conforme Toaldo ${ }^{35}$, a mediação como forma alternativa de resolução de conflito ajuda também no combate à Síndrome de Alienação Parental, pois, o trabalho com profissionais de diversas áreas ajuda os genitores a estarem conscientes de seus papeis e de sua responsabilidade para o fim do conflito.

A mediação é uma forma de evitar a judicialização do conflito levando as próprias partes a serem responsáveis por suas decisões, pela condução de suas vidas. O mediador apenas ajuda na reflexão, na busca de alternativas, no diálogo, mas a decisão final cabe sempre às partes. Essa oportunidade de reflexão e responsabilidade por seus atos e decisões pode evitar a instalação da SAP, pois, muitas vezes os genitores estão tão preocupados com seus problemas, em vencer a contenda, em buscar um culpado que acabam se esquecendo dos direitos de seus filhos.

\footnotetext{
${ }^{34}$ LAGRASTA NETO, Caetano. Direito de Família: A família brasileira no final do século XX. São Paulo: Malheiros, 2000. p. 102.

35 TOALDO, A.M. A mediação como instrumento eficaz na busca pela solução da Alienação Parental. Disponível em http://www.ambitojuridico.com.br/site/index.php?n_link=revista_artigos_leitura\&tartigo_id=6723. Acesso em 04 de Agosto de 2011
} 
Lowenstein apud França ${ }^{36}$ traz alguns meios de lidar e tentar combater a alienação parental durante a mediação:

1. Desfazer o efeito da depreciação por um dos pais para com o outro, tornar a criança consciente da história feliz que havia antes da separação.

2. Mostrar os pontos positivos sobre o genitor denegrido.

3. Ser firme quanto à mudança de atitudes e comportamentos que estejam causando a alienação parental.

4. Tentar obter a cooperação do genitor alienador para que pare com a alienação, se esse processo já estiver se instalado, impedir de dar início a ele.

5. Atender a criança inicialmente sozinha, para obter algumas informações sobre o modo como ela se sente a respeito do genitor ausente, e também, depois, separadamente de cada genitor.

6. Conversar com a criança a respeito da injustiça e da crueldade que há em se rejeitar um pai amoroso.

7. Conscientizar a criança de que ela precisa de ambos os pais.

8. Encorajar a criança não só a dialogar com o genitor alienado, como também os familiares por parte deste, incluindo avós, avôs, tias, tios, primos etc

9. Reduzir ou eliminar as chamadas telefônicas e outras comunicações do genitor alienante com a criança enquanto ela está com o outro genitor, isto é, durante uma visitação.

10. Incentivar as crianças que estão sendo alienadas a passar tanto tempo quanto possível sozinha com o genitor alienado, para que se possa desenvolver ou re-desenvolver o relacionamento entre eles.

11. O mediador quando perceber que não houve progressos para inverter o processo de alienação, deve sugerir ao juízo ou tribunal que a guarda da criança fique com o genitor não alienante.

\footnotetext{
${ }^{36}$ FRANÇA, G. S. V. a Síndrome da Alienação Parental: Importância do valor e da conscientização da mediação familiar Disponível em: http://www.derechoycambiosocial.com/revista018/alienacion\%20parental.htm. Acesso em 04/08/2011
} 
12. Em casos extremos de grandes danos psicológicos o mediador deverá sugerir ao juízo ou tribunal a remoção da criança para um local neutro por um tempo, ou colocá-la sob cuidados do Estado para evitar uma maior alienação.

13. Em alguns casos encontrar junto com os genitores uma pessoa neutra que possa intermediar o contato entre a criança e o pai ausente.

14. Lembrar que a criança que foi vítima de manipulação mental, precisa saber que é seguro estar com o genitor alienado, sem que isso implique em redução de sua lealdade e compromisso para com o outro progenitor que tenha a guarda.

15. Concentrar o discurso sobre o passado e os tempos felizes juntos e como isso pode continuar no futuro.

Para amenizar os males causados pela alienação parental, o genitor alienador poderá ter que se afastar do filho e ser submetido à tratamento psicológico. Isto deve ocorrer para que a criança vá aos poucos percebendo a realidade dos fatos, contudo, o afastamento não deve ser total nem feito bruscamente para evitar mais danos à criança.

A mediação pode interferir na questão da Síndrome de Alienação Parental, pois, esta tende a ocorrer no processo de divórcio, principalmente durante a disputa pela guarda dos filhos, e, o ex casal que tenha passado pela fase da mediação, tendo refletido, dialogado e feito concessões mútuas, tende a lidar melhor com o fim do relacionamento, não atuando desta maneira de modo a incitar na criança ódio contra o outro genitor.

Mesmo que não seja possível, através da mediação, exterminar a ocorrência da Síndrome de Alienação Parental, ela certamente ajuda a evitá-la e a minimizar seus efeitos através da reflexão, diálogo e responsabilidade por decisões e comportamentos dos genitores para com seus filhos.

\section{CONCLUSÃO}

A família é responsável pelos cuidados da criança em desenvolvimento e por sua saúde física, psicológica e social.

É direito de toda criança a convivência familiar saudável e harmoniosa.Esse direito está garantido em nossa Lei Máxima, a Constituição Federal. 
Para garantir uma convivência saudável e harmoniosa os operadores da Psicologia e do Direito precisam estar atentos ao surgimento de situações que impeçam a criança de conviver com ambos os genitores e seus familiares, mesmo com o fim da união de seus pais.

O entendimento atual, inclusive dado pela legislação brasileira, é de que a obrigação de cuidar e educar os filhos é decorrente do vínculo gerado pela filiação e não do casamento.

Muitas vezes, as pessoas que se divorciam não conseguem discernir o que é próprio do casal, do que é referente ao seu papel parental. A raiva, a mágoa do ex-cônjuge e a incompreensão pelo fim da união, podem ter como conseqüência a imposição do distanciamento dos filhos

A Síndrome de Alienação Parental, onde um genitor treina o filho para romper os laços afetivos com o outro genitor e afasta a criança de seu convívio pode deixar marcas por toda a vida. O vínculo entre a criança e o genitor alienado restará destruído se o rompimento for por muitos anos.

A mediação familiar oferece a oportunidade de reflexão e diálogo por parte dos genitores em processo de divórcio, o que é preferível à uma ação na justiça.

Diante do exposto, percebemos que o papel do mediador é de extrema importância para identificar a ocorrência de Alienação Parental no processo de mediação familiar.

Conclui-se, portanto, que o mediador deve estar atento ao surgimento de situações como a Síndrome de Alienação Parental devendo intervir o mais rápido possível para impedir que os danos causados pela Alienação se tornem irreversíveis. Contudo, se a possibilidade de entendimento falhar, deve-se, então, recorrer ao sistema judicial.

\section{REFERÊNCIAS}

AGUILAR, José Manuel. Síndrome de alienação parental: filhos manipulados por um cônjuge para odiar o outro. Casal de Cambra: Caleidoscópio, 2008.

BRASIL. Constituição da República Federativa do Brasil. 8. ed. São Paulo: Revista dos Tribunais, 2003. RT Legislação.

.Lei 12.318 de 26 de agosto de 2010. Dispõe sobre alienação parental e altera o art.236 da Lei n8069 de 13 de julho de 1990. Disponível em Acesso em 25.ago de 2011.

BREITMAN Stella; PORTO, Alice Costa.Mediação Familiar: Uma intervenção em busca da paz. Porto Alegre: Criação Humana, 2001 
CALÇADA, Andréia. Falsas acusações de abuso sexual: parâmetros iniciais para uma avaliação. In: Associação de Pais e Mães Separados. Guarda compartilhada: aspectos psicológicos e jurídicos. Porto Alegre: Equilíbrio, 2005

CARREIRA ET AL, 2000; KELLEY, SMITH, GREEN BERNDT \& ROGERS, 1998; SHANNON, TAMIS LE MONDA, LONDON E CABRERA In: PAPALI, D.E.; OLDS, S.W; FELDMAN, R.D. 0 mundo da criança: da Infância à adolescência. São Paulo: McGraw - Hill, 2009

CASTRO, L.R. Disputa de guarda e visitas: no interesse dos pais ou dos filhos? São Paulo: Casa do Psicólogo, 2003

CONSELHO NACIONAL DE JUSTIÇA RESOLUÇÃO N 125, DE 29 DE NOVEMBRO DE 2010.

Disponível em: http://www.cnj.jus.br/atos-administrativos/atos-da-presidencia/323-

resolucoes/12243-resolucao-no-125-de-29-de-novembro-de-2010. Acesso em 16 ago. de 2011

DIAS, Maria Berenice. Síndrome da alienação parental, o que é isso? . Jus Navigandi, Teresina, ano 10, n. 1119, 25 jul. 2006. Disponível em:

<http://jus2.uol.com.br/doutrina/texto. asp?id=8690>. Acesso em: 21 maio de 2010.

Manual de Direito de Família. 6.ed. São Paulo: Revistas dos Tribunais, 2010

FERRAZ, Taís Schilling A conciliação e sua efetividade na solução dos conflitos. Disponível em: portal.tjpr.jus.br/c/document_library/get_file?folderld=328895...doc. Acesso em: 01- agosto2011

Fiorelli, J.O ; MALHADAS, M.J. Psicologia aplicada ao direito São Paulo: Ltr,2006.

FRANÇA, G. S. V. a Síndrome da Alienação Parental: Importância do valor e da conscientização da mediação familiar Disponível em:

http://www.derechoycambiosocial.com/revista018/alienacion\%20parental.htm._Acesso em 04. ago de 2011

GARCIA, E.M.S. Direito de Família: Principio da Dignidade da Pessoa Humana. Leme: Editora de Direito, 2003

GARDNER, Richard A. O DSM-IV tem equivalente para o diagnóstico de Síndrome de Alienação Parental (SAP)? Disponível em http: / / www. alienacaoparental.com.br/textos-sobre-sap-1/odsm-iv-tem-equivalente. Acesso em 20 maio de 2010

GRISARD FILHO, Waldyr. Guarda Compartilhada - Quem Melhor para Decidir? São Paulo: Pai Legal, 2002. Disponível em:

<http: / / www.pailegal.net/TextoCompleto. asp?lsTextoTipo=Justica\& offset=10\&lsTextold=109497 2355>. Acesso em: 15 ago. de 2011.

LAGRASTA NETO, Caetano. Direito de Família: A família brasileira no final do século XX. São Paulo: Malheiros, 2000. p. 102.

LÔBO, Paulo Luiz Netto. Direito Civil: Famílias. 2. ed. São Paulo: Saraiva, 2009. 
MOTTA, Maria A. P. A Síndrome da Alienação Parental In: Associação de Pais e Mães Separados. Síndrome de alienação parental e a tirania do guardião. Porto Alegre: Equilíbrio, 2008.

NAZARETH, E.R. Guia de mediação familiar: aspectos psicológicos In: NAZARETH, E.R. VILELA, S.R., GUEDES- PINTO, A.C.R. Mediação familiar. São Paulo: Equilibrio, 2009

RESENDE, M. SILVA, E.L. Síndrome da Alienação Parental: A exclusão de um terceiro. In: Associação de Pais e Mães Separados. Síndrome de alienação parental e a tirania do guardião. Porto Alegre: Equilíbrio, 2008.

ROSA, Conrado Paulino da; SPENGLER, Fabriana Marion. A mediação como Política Pública de tratamento dos conflitos familiares. In: RODRIGUES, Hugo Thamir; COSTA, Marli M. M. da. (org.). Direito e Políticas Públicas III. Porto Alegre: Imprensa Livre, 2009, v. III, p. 155-178.

SALES, Lília Maia de Morais. Justiça e mediação de conflitos. Belo Horizonte: Del Rey, 2004.

SALES, Lília Maia de Morais; VASCONCELOS, Mônica Carvalho. Mediação familiar, um estudo histórico-social das relações de conflitos nas famílias contemporâneas. Fortaleza: Expressão Gráfica, 2006.

SAMPAIO, L.R.C. NETO, A.B. O que é mediação de conflitos. São Paulo: Brasiliense, 2007.

SILVA, Evandro L. Guarda de filhos: aspectos psicológicos. In: Associação de Pais e Mães Separados. Guarda compartilhada: aspectos psicológicos e jurídicos. Porto Alegre: Equilíbrio, 2005.

SILVA, Denise M. P. Psicologia jurídica no processo civil brasileiro. $1^{\text {a }}$. e.d. São Paulo: Casa do Psicólogo, 2003

SOUZA, R.M. RAMIRES, V.R. Amor, casamento, família e divórcio...e depois, segundo às crianças.São Paulo: Summus, 2006.

TEYBER E. Ajudando crianças a conviver com o divórcio. São Paulo: Nobel, 1995

TOALDO, A.M. A mediação como instrumento eficaz na busca pela solução da Alienação Parental. Disponível em http: //www.ambito-

juridico.com.br/site/index.php?n_link=revista_artigos_leitura\&tartigo_id=6723. Acesso em: 04 ago. 2011

Recebido em: 17.09.2013

Correções em: 26.11.2013

Aprovado em: 29.12.2013 